WORLD VIEW

\title{
Visual and ocular findings in children adopted from eastern Europe
}

\author{
M A Grönlund, E Aring, A Hellström, M Landgren, K Strömland
}

Series editors: W V Good and S Ruit

Br J Ophthalmol 2004;88:1362-1367. doi: 10.1136/bjo.2004.042085

See end of article for authors' affiliations .....................

Correspondence to: Marita Andersson Grönlund, MD, Department of Pediatric Ophthalmology, The Queen Silvia Children's Hospital, Sahlgrenska University Hospital/East, SE 41685 Göteborg, Sweden; marita. gronlund@oft.gu.se

Accepted for publication 23 April 2004
Aims: To evaluate ophthalmological findings in children adopted from eastern Europe.

Methods: A prospective study on 72/99 children, born 1990-5 and adopted from eastern Europe to western Sweden during 1993-7 was performed. The children (41 boys; mean age 7.5 years) were compared with an age and sex matched reference group ("ref") of Swedish children.

Results: $78 \%$ of the adopted children had abnormal ocular findings. $26 \%$ (ref $4 \%$ ) had visual acuity (VA) of the better eye $\leqslant 0.5(\geqslant 0.3 \log M A R)(p=0.0001)$ and $8 \%($ ref $0 \%)$ were visually impaired $(p=0.01)$. Amblyopia was found in $15 \%(\mathrm{ref} 2 \%)(p=0.005)$. $22 \%$ (ref $10 \%$ ) were hyperopic ( $\geqslant 2.0 \mathrm{D} \mathrm{SE})$ (NS) and $10 \%($ ref $1 \%$ ) were myopic ( $\geqslant 0.5 \mathrm{D} \mathrm{SE})(p=0.03)$. Astigmatism ( $\geqslant 0.75 \mathrm{D}$ ) was found in $51 \%$ (ref $23 \%$ ) $(p=0.004)$. $32 \%$ (ref $2 \%)$ had strabismus $(p<0.0001)$, mostly esotropia. Four cases had bilateral optic nerve hypoplasia, in three of whom a history of suspected prenatal alcohol exposure was documented. One child had congenital glaucoma. Signs of visuoperceptual problems were recorded in 37\% (ref 1\%) $(p<0.0001)$.

Conclusion: In this study, children adopted from eastern Europe had a high frequency of ophthalmological findings. Consequently, it is strongly recommended that an ophthalmological examination be performed in these children after arrival in their new home country.
$\mathrm{T}$ he number of children adopted from eastern Europe has increased during the past decades, with a marked increase particularly during the 1990s. Between 1969 and 2000, over 2500 children out of a total of 41000 adoptees from non-Nordic countries were adopted in Sweden from Poland, Romania, and the former Soviet Union. These countries are now a main source of international adoptions, accounting for 27\% of all children placed in Sweden in 1997.

In 1997, Albers et al ${ }^{1}$ reported that adopted children from eastern Europe in the United States were growth delayed and developmentally delayed at arrival. The children $(n=56)$ demonstrated delayed development regarding gross motor skills in $70 \%$, fine motor control in $82 \%$, language skills in $59 \%$, and social/emotional skills in 53\% of cases. Nearly $45 \%$ were growth retarded with regard to body weight and head circumference and $68 \%$ with regard to length. In a couple of studies, ${ }^{2}{ }^{3}$ only $13-15 \%$ of children adopted from Romania were reported to be physically healthy, normally developed, and without significant psychosocial symptoms. Six per cent of 111 children who were adopted into UK families from Romania showed autistic-like patterns of behaviour and another $6 \%$ showed milder autistic features. ${ }^{4}$ The children were developmentally retarded when entering the United Kingdom but the developmental catch up at 4 years was good, although not complete, in those children who were adopted after 6 months of age. ${ }^{5}$ Rutter et al, ${ }^{6}$ who compared 165 children adopted from Romania with 52 non-deprived within UK adoptees, concluded that profound early institutional privation tends to be particularly associated with attachment disorder behaviours, inattention/overactivity, and quasi-autistic behaviour.

Single cases of ocular findings, such as strabismus and optic nerve hypoplasia (ONH), have previously been reported, ${ }^{1}$ and in our clinical work we had previously met children adopted from eastern Europe who had various ophthalmological findings. However, to our knowledge, no detailed ophthalmological examination has been performed in a larger number of adopted children. Therefore, the aim of this study, which is part of a multidisciplinary study, was to evaluate ophthalmological findings in a group of children adopted in Sweden from eastern Europe.

\section{METHODS}

All children ( $\mathrm{n}=99,54$ boys and 45 girls) born between 1990 and 1995, adopted during 1993-7 from Poland, Romania, Russia, Estonia, and Latvia through an authorised adoption agency in Sweden, and living in the region Västra Götaland, were invited to participate in the study. There were 19 parental refusals and four non-respondents. Seventy two children, 41 boys and 31 girls, with a mean age of 7.5 years (range 4.8-10.5 years), were examined (fig 1). All medical records available of another four children (three boys, one girl, mean age 8.9 years) from Romania $(n=2)$, Estonia $(\mathrm{n}=1)$, and Russia $(\mathrm{n}=1)$ were scrutinised. Consequently, 76 children $(77 \%)$ were available for background data and 72 $(73 \%)$ were examined and included in the present study. There was no difference regarding sex and age between the participants and the non-participants. Twelve of the nonparticipants came from Romania, three came from Russia, and eight came from Poland. Contacts have been possible to be taken with 13 of the 19 parents, who refused to participate in the study. The reason for not participating was frequent contacts with other doctors in four cases, in two of which there were ophthalmological abnormalities. In the other nine children the parents gave information that they have no regular medical contact.

Information regarding the perinatal period was obtained from medical records from the birth countries, which were available in 67 out of the 72 children (93\%). Birth weight, birth length, and head circumference at birth were converted into standard deviation scores (SDS) based on Swedish

Abbreviations: FAS, fetal alcohol syndrome; IUAE, intrauterine alcohol exposure; logMAR, log of the minimal angle of resolution; $\mathrm{ONH}$, optic nerve hypoplasia; $\mathrm{pD}$, prism dioptres; SDS, standard deviation scores; $\mathrm{SE}$, spherical equivalent; SGA, small for gestational age 


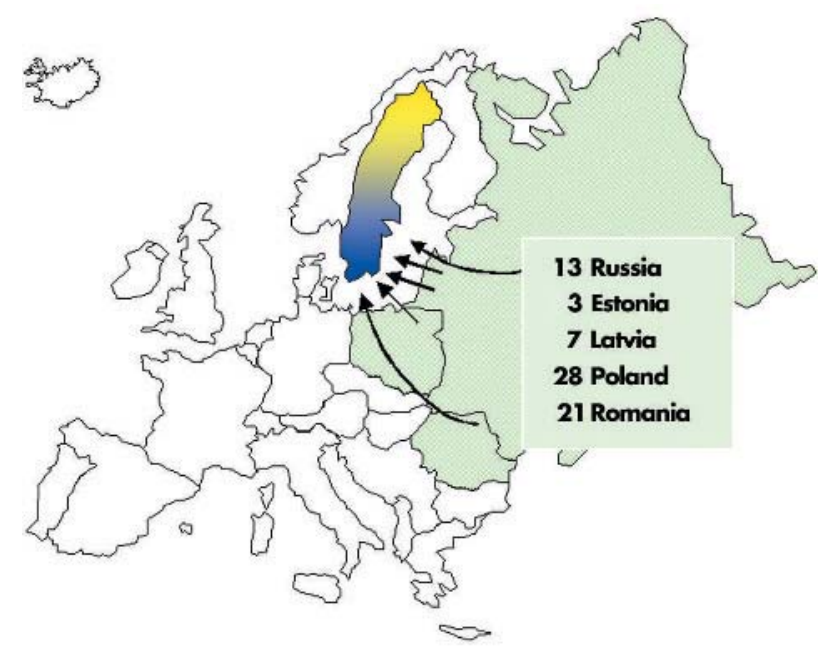

Figure 1 Seventy two children adopted in western Sweden from Poland $(n=28)$, Romania $(n=21)$, Russia $(n=13)$, Latvia $(n=7)$, and Estonia $(\mathrm{n}=3)$.

reference values, and are shown in table 1. Altogether, 28 out of 61 children $(47 \%)$ were born small for gestational age (SGA) (birth weight $\leqslant-2$ SDS) and 22 out of the 72 children $(30 \%)$ were considered born preterm $(<37$ weeks of gestational age). Ten of the children (14\%) were twins. The children's mean age at the time of adoption was 2.8 years and the children had stayed at an orphanage for a mean of 2 years before adoption. Twenty four children (33\%) had a history of suspected prenatal alcohol exposure. Detailed data regarding the background of the children participating in the study will be presented elsewhere (Landgren $M$, unpublished data, 2004).

The children were examined during April 2000 to September 2002 at the Queen Silvia Children's Hospital, Göteborg, and at the Hospital of Mariestad, Mariestad, Sweden, by a multidisciplinary team consisting of a paediatric ophthalmologist, orthoptist, paediatrician/neuropaediatrician, and psychologist. Ophthalmological and perinatal data were compared with data for an age and sex matched reference group ("ref") $(\mathrm{n}=90,39$ girls and 51 boys, mean age 7.6 years (range $4.1-11.4$ years) consisting of Swedish children living in the same area as the adoptees. Birth weight, birth length, and head circumference at birth of the reference group were converted into SDSs and are shown in table 1. Four children from this group (4.4\%) were born preterm and no child was born SGA. The reference group was tested under identical conditions as the study cohort.

A detailed ophthalmological examination was performed, including the following.

\section{Determination of visual acuity for near and distant fixation}

Visual acuity (VA) was tested with a linear KM-Boks chart, which is an arithmetically based letter matching chart with seven different letters (C D E F K N V) of equal readability. ${ }^{7}$ If a child could not manage to read the KM-Boks chart the HOTV chart was used. Distance VA was tested monocularly at a distance of 3 metres and near vision was tested binocularly at a distance of 0.33 metres. Amblyopia was defined as a difference in VA between the eyes of at least two lines, which could not be explained by structural abnormalities in the eye.

\section{Refraction under cycloplegia}

This was performed with an autorefractor (Topcon A6 300) after a single instillation of a mixture of cyclopentolate
Table 1 Birth weight, birth length, and head circumference at birth converted into standard deviation scores (SDSs) based on Swedish reference values in the group of adopted children from eastern Europe and in the reference group

\begin{tabular}{|c|c|c|}
\hline & Adopted children & Reference group \\
\hline SDS & Mean (range) & Mean (range) $(n=90)$ \\
\hline $\begin{array}{l}\text { Birth weight SDS } \\
\text { Birth length SDS } \\
\text { Head circumference } \\
\text { at birth SDS }\end{array}$ & $\begin{array}{l}-1.7(-5.0-1.5)^{*} \\
-0.3(-5.0-4.0) \dagger \\
-1.2(-6.0-2.0) \ddagger\end{array}$ & $\begin{array}{l}0.16(-2.5-5.5) \\
0.25(-2.0-4.0) \\
-0.15(-4.0-4.0) \S\end{array}$ \\
\hline
\end{tabular}

$(0.85 \%)$ and phenylephrine (1.5\%). Significant refractive errors were defined as a spherical equivalent (SE) of myopia $\geqslant 0.5$ dioptres (D) or hyperopia $\geqslant 2.0 \mathrm{D}$. Astigmatism was assessed at a level of $\geqslant 0.75 \mathrm{D}$ and anisometropia of $\geqslant 1.0 \mathrm{D}$ SE.

\section{Investigation of strabismus and ocular motility}

Heterotropia was detected with cover test and defined as manifest or intermittent manifest deviation of $\geqslant 2$ prism dioptres $(\mathrm{pD})$ and the nomenclature was esotropia, exotropia, hypotropia, and hypertropia. Heterophoria was detected with alternating cover test and defined as a latent deviation of $\geqslant 2$ pD. Motility was tested grossly for pareses of extraocular muscles.

\section{Testing of stereo acuity}

This was done with the TNO random dot stereo test, the Lang I stereo card, or the Titmus test where appropriate. Subnormal stereo acuity was defined as $>60$ seconds of arc. It was considered absent if all three tests were negative.

\section{Examination of the anterior segment, media, and ocular fundus}

Examination of the anterior segment of the eye was performed with a slit lamp and the ocular fundus was examined by indirect ophthalmoscopy. Occurrence of nystagmus was noted. Fundus photographs were taken.

\section{Examination of visual fields}

Examination of visual fields was performed with a Goldmann perimeter (outer limits) using the V-4 target. The presence of large defects such as hemianopia and quadrantanopia was looked for.

\section{Histroy of visual perception}

A structured history taking was performed regarding visuoperceptual problems in five different areas-namely, recognition, orientation, perception of depth and motion, and simultaneous perception. ${ }^{8}$

Medical records from the birth countries, of the first paediatric examination after arrival in Sweden, and from Swedish child healthcare centres, schools and, where appropriate, outpatients clinics and wards were collected and scrutinised. The study was approved by the ethics committee at the Medical Faculty, Sahlgrenska Academy at Göteborg University, Göteborg, Sweden. Informed consent was obtained from the parents of all the children participating in the study.

\section{Statistical analysis}

Means, standard deviations (SDs), medians, and ranges were calculated for descriptive purposes. For a comparison between two groups, Mann-Whitney $U$ test was used for 
Table 2 Visual acuity (VA) at distance (better eye) (A) and VA at near (binocular) (B) in the group of adopted children from eastern Europe compared with a Swedish reference group

\begin{tabular}{|c|c|c|c|}
\hline Decimal (logMAR) & No (\%) & No (\%) & \\
\hline $\begin{array}{l}\text { (A) Visual acuity at distance in the } \\
\text { better eye }\end{array}$ & $\begin{array}{l}\text { Adopted children } \\
(n=72)\end{array}$ & $\begin{array}{l}\text { Reference group } \\
(n=90)\end{array}$ & p Value \\
\hline $\begin{array}{l}\leqslant 0.3(\geqslant 0.5) \\
0.4-0.65(0.4-0.2) \\
0.8-1.0(0.1-0.0)\end{array}$ & $\begin{array}{l}6(8) \\
29(40) \\
37(52)\end{array}$ & $\begin{array}{l}0(0) \\
12(13) \\
78(87)\end{array}$ & $\begin{array}{l}0.01 \\
0.0002 \\
<0.0001\end{array}$ \\
\hline (B) Visual acuity at near & Adopted children $(n=70)$ & Reference group $(n=90)$ & \\
\hline $\begin{array}{l}\leqslant 0.3(\geqslant 0.5) \\
0.4-0.65(0.4-0.2) \\
0.8-1.0(0.1-0.0)\end{array}$ & $\begin{array}{l}4(6) \\
30(43) \\
36(51)\end{array}$ & $\begin{array}{l}1(1) \\
12(13) \\
77(86)\end{array}$ & $\begin{array}{l}0.2 \\
0.0001 \\
<0.0001\end{array}$ \\
\hline
\end{tabular}

ordered and continuous variables; for dichotomous variables, Fisher's exact test was used. All tests were two tailed and conducted at the 5\% significance level. Test results were considered to be significant if $\mathrm{p}<0.05$. The reference group for this study was selected individual by individual by minimising the maximal $t$ values between the group of adopted children and a reference group of healthy Swedish school aged children, over the variables age and sex.

\section{RESULTS}

\section{Ophthalmological data}

Fifty six of the 72 adopted children (78\%) had ocular findings of significance $(\operatorname{ref} 29 \% ; \mathrm{n}=26)(\mathrm{p}<0.0001)$.

\section{Visual acuity}

Visual acuity at distance $(n=72)$ and at near $(n=70)$ of the adopted children compared with the reference group is shown in table $2 \mathrm{~A}$ and $2 \mathrm{~B}$. Six of the children $(8 \%)$ (ref $0 \%$ ) had VA $\leqslant 0.3(\geqslant 0.5 \log$ of the minimal angle of resolution $(\log M A R)$ in the best eye $(p=0.01)$. Nineteen children $(26 \%)$ (ref $4 \%)$ had VA in the best eye of $\leqslant 0.5(\geqslant 0.3 \log \mathrm{MAR})$ $(\mathrm{p}=0.0001)$. A notably high proportion of the adopted children $(49 \%)$ had subnormal VA $(<0.8 ;>0.1 \log M A R)$. Eleven of the adopted children (15\%) (ref 2\%) were amblyopic $(\mathrm{p}=0.005)$.

\section{Refraction}

Table 3 shows the number of adopted children and controls who were myopic and hyperopic as well as those who had astigmatism. The astigmatism of the adopted children ranged from 0.75 to $6.0 \mathrm{D}$. Refraction after cycloplegia for right and left eyes, respectively, is shown in figure $2 \mathrm{~A}$ and $\mathrm{B}$. Anisometropia was recorded in six children (8\%) (ref 1\%) (NS). Twenty six children (36\%) (ref 7\%) wore glasses $(\mathrm{p}<0.0001)$ at the time of the investigation.
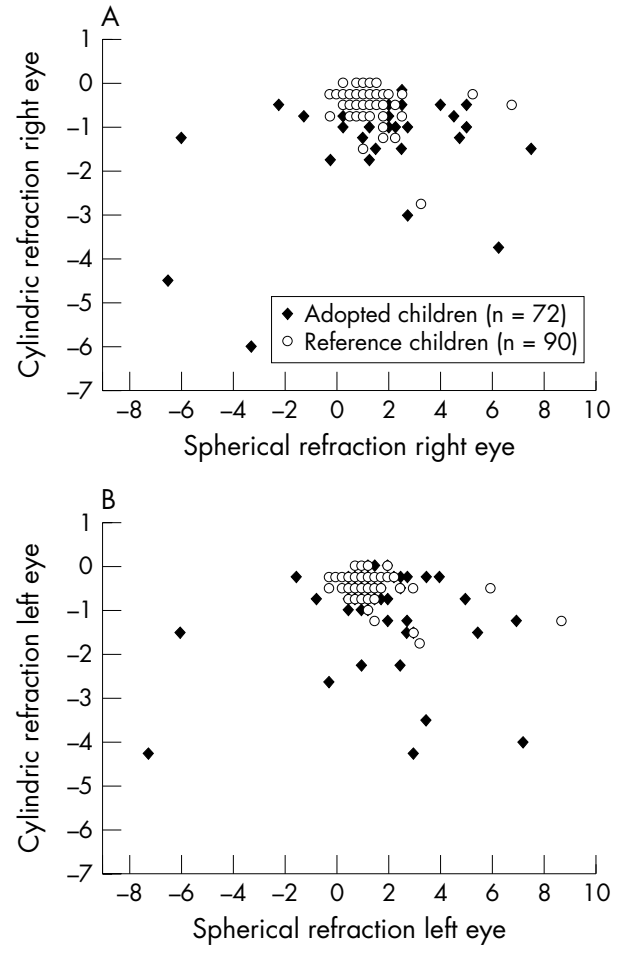

Figure 2 Refraction under cycloplegia for right (A) and left (B) eyes in 72 adopted children and in 90 age and sex matched controls.

\section{Strabismus and ocular motility}

Table 4 shows the proportion of strabismus among the adopted children and the reference group. The esotropia:exotropia ratio was 2.3:1. Nine of the 23 children (39\%) with heterotropia also had refractive errors $\geqslant+3 \mathrm{D}$ SE or $\leqslant-3 \mathrm{D}$

Table 3 Number and percentage of adopted children from eastern Europe and controls who after cycloplegia were measured to be hyperopic ( $\geqslant 2.0 \mathrm{D} \mathrm{SE}$ ) and myopic ( $\geqslant 0.5 \mathrm{D}$ $\mathrm{SE})$, as well as children who were astigmatic ( $\geqslant 0.75 \mathrm{D}$ )

\begin{tabular}{|c|c|c|c|}
\hline & Adopted children ( $n=72$ ) & Ref group $(n=90)$ & \\
\hline Refraction (D) & No $(\%)$ & No $(\%)$ & p Value \\
\hline Myopia ( $\geqslant 0.5$ D SE) & $7(10)$ & $1(1)$ & 0.03 \\
\hline Hyperopia ( $\geqslant 2.0$ D SE) & $16(22)$ & $9(10)$ & 0.06 \\
\hline Astigmatism $(\geqslant 0.75 \mathrm{D})$ & $37(51)$ & $21(23)$ & 0.0004 \\
\hline
\end{tabular}




\begin{tabular}{|c|c|c|c|}
\hline \multirow[b]{2}{*}{ Strabismus } & \multirow{2}{*}{$\begin{array}{l}\text { Adopted children }(n=72) \\
\text { No }(\%)\end{array}$} & \multirow{2}{*}{$\begin{array}{l}\text { Reference group }(n=90) \\
\text { No }(\%)\end{array}$} & \multirow[b]{2}{*}{$\mathrm{p}$ Value } \\
\hline & & & \\
\hline Heterotropia & $23(32)$ & $2(2)$ & $<0.0001$ \\
\hline Manifest deviation & $19(83)$ & $2(2)$ & $<0.0001$ \\
\hline Intermittent deviation & $4(17)$ & $0(0)$ & 0.07 \\
\hline Esotropia & $16(22)$ & $2(2)$ & 0.0001 \\
\hline Exotropia & $7(10)$ & $0(0)$ & 0.006 \\
\hline Heterophoria & $23(32)$ & $23(26)$ & 0.5 \\
\hline
\end{tabular}

SE in the more ametropic eye, which corresponded to the findings in all of the children with such refractive errors. There was no difference regarding such refractive errors between the esotropia and exotropia groups. One boy was found to have a unilateral partial paresis of the third cranial nerve. Nystagmus was noted in two children.

\section{Stereo acuity}

Sixteen out of 71 adopted children (23\%) (ref 1\%) lacked stereovision $(\mathrm{p}<0.0001)$ and 15 children $(21 \%)$ (ref $1 \%)$ had subnormal stereo acuity $(\mathrm{p}<0.0001)$, while 40 children $(56 \%)$ (ref 98\%) had normal stereo acuity $(\mathrm{p}<0.0001)$. All children with absent stereo acuity and five of the 15 children with subnormal stereo acuity had heterotropia. Seven of the children with subnormal stereovision had heterophoria and two had othophoria. Two other children with subnormal stereo acuity $\left(240^{\prime \prime}\right)$ had subnormal VA as well. However, one child with intermittent exotropia had normal stereopsis.

\section{Anterior segment, media, and ocular fundus}

Four children had ptosis and epicanthal folds were found in seven children. One child had congenital glaucoma with macrocornea and cataract, which he had been operated for. Another boy had small opacities in the centre of his lenses and old synechiae in both eyes. Bilateral corneal dystrophy was found in another child. Four cases of bilateral ONH were observed (table 5).

\section{Visual fields}

Visual fields were examined in 60 children (83\%). In 12 children, we could not perform the test. Fifty three children (88\%) had normal outer limits of their visual fields; seven children (12\%) had some generally constricted outer limits. No hemianopsias or quadrantanopsias were found.

\section{Visual perception}

A structured history taking regarding visuoperceptual problems was performed in 65 children. Twenty four of these (37\%) (ref $1 \%$ ) showed signs of cognitive visual problems, according to the structured interview in one or more (median 2 , range 1-4) of the following areas: recognition, orientation, depth perception, motion perception, or simultaneous perception $(p<0.0001)$ (fig 3$)$. The most frequent area of visuoperceptual problems reported was depth perception $(n=15)$, followed by orientation $(n=8)$, simultaneous perception $(n=8)$, motion perception $(n=7)$, and recognition $(\mathrm{n}=3)$.

\section{Ophthalmological information obtained from birth countries}

Ophthalmological notes were found in $51 \%(n=34 / 67)$ of the files from the birth countries. Twenty one of the children were supposed to have tested normal at an ophthalmological examination. Strabismus had been noted in six children, one of whom had undergone strabismus surgery, and hyperopia and myopia had been recorded in one child each. Haemangioma and Horner's syndrome had been noted in one child and another had been reported to have "abnormal visual behaviour." Eye infections of various causes had been recorded in three children. Consequently, 10 out of 72 children (14\%) had a previous record of some ophthalmological finding of significance.

\section{Ophthalmological data obtained from Swedish medical records before our investigation}

The paediatricians who had examined the children after arrival in Sweden had referred $15(21 \%)$ of the children to an eye clinic for further evaluation. Before our investigation, 50 children $(69 \%)$ had been examined by an ophthalmologist and/or an orthoptist in Sweden. Our investigation resulted in

Table 5 Ophthalmological and prenatal/perinatal findings in four children with bilateral optic nerve hypoplasia (ONH) adopted from eastern Europe

\begin{tabular}{|c|c|c|c|c|c|c|c|c|}
\hline $\begin{array}{l}\text { Case/sex/ } \\
\text { age (years) }\end{array}$ & $\begin{array}{l}\text { VA decimal } \\
\text { (logMAR) } \\
\text { RE/LE }\end{array}$ & $\begin{array}{l}\text { Refraction sphere/cyl } \\
\text { RE/LE }\end{array}$ & $\begin{array}{l}\text { Strabismus/ocular } \\
\text { motility }\end{array}$ & $\begin{array}{l}\text { Stereo } \\
\text { acuity }\end{array}$ & $\begin{array}{l}\text { Anterior segment/ } \\
\text { media/fundus }\end{array}$ & $\begin{array}{l}\text { GA } \\
\text { (weeks) }\end{array}$ & $\begin{array}{l}\text { Birth weight } \\
\text { (g)/(SDS) }\end{array}$ & $\begin{array}{l}\text { Prenatal/ } \\
\text { perinatal } \\
\text { history }\end{array}$ \\
\hline $1 / F / 8$ & $\begin{array}{l}0.4 / 0.1 \\
(0.4 / 1.0)\end{array}$ & $\begin{array}{l}+4.75 /-1.25 \\
+2.75 /-1.25\end{array}$ & Esotropia, nystagmus & No stereo & Ptosis & 35 & $2050 /-2.2$ & $\begin{array}{l}\text { Preterm, SGA, } \\
\text { IUAE }\end{array}$ \\
\hline $2 / F / 6$ & $\begin{array}{l}0.3 / 0.4 \\
(0.5 / 0.4)\end{array}$ & $\begin{array}{l}+1.25 /-0.75 \\
+1.25 /-1.0\end{array}$ & Esophoria & $240^{\prime \prime}$ & Epicanthial folds & $38 / 39$ & $2042 /-5.0$ & SGA, IUAE \\
\hline $3 / F / 6$ & $\begin{array}{l}0.4 / 0.5 \\
(0.4 / 0.3)\end{array}$ & $\begin{array}{l}+0.75 /-0.5 \\
+0.75 /-0.5\end{array}$ & Exophoria & $240^{\prime \prime}$ & $\begin{array}{l}\text { Tortuosity of retinal } \\
\text { vessels }\end{array}$ & unknown & $\begin{array}{l}3000 \text { at } \\
6 \text { months of } \\
\text { age }\end{array}$ & IUAE \\
\hline $4 / M / 7$ & $\begin{array}{l}0.65 / 0.65 \\
(0.2 / 0.2)\end{array}$ & $\begin{array}{l}+3.0 /-0.5 \\
+3.25 /-1.5\end{array}$ & Exophoria & $240^{\prime \prime}$ & $\begin{array}{l}\text { Tortuosity of retinal } \\
\text { vessels }\end{array}$ & 32 & $1578 /-2.1$ & Preterm, SGA \\
\hline
\end{tabular}

IUAE, suspected intrauterine alcohol exposure; GA, gestational age; logMAR, log of the minimal angle of resolution; SDS, standard deviation score; SGA, small for gestational age; VA, visual acuity. 

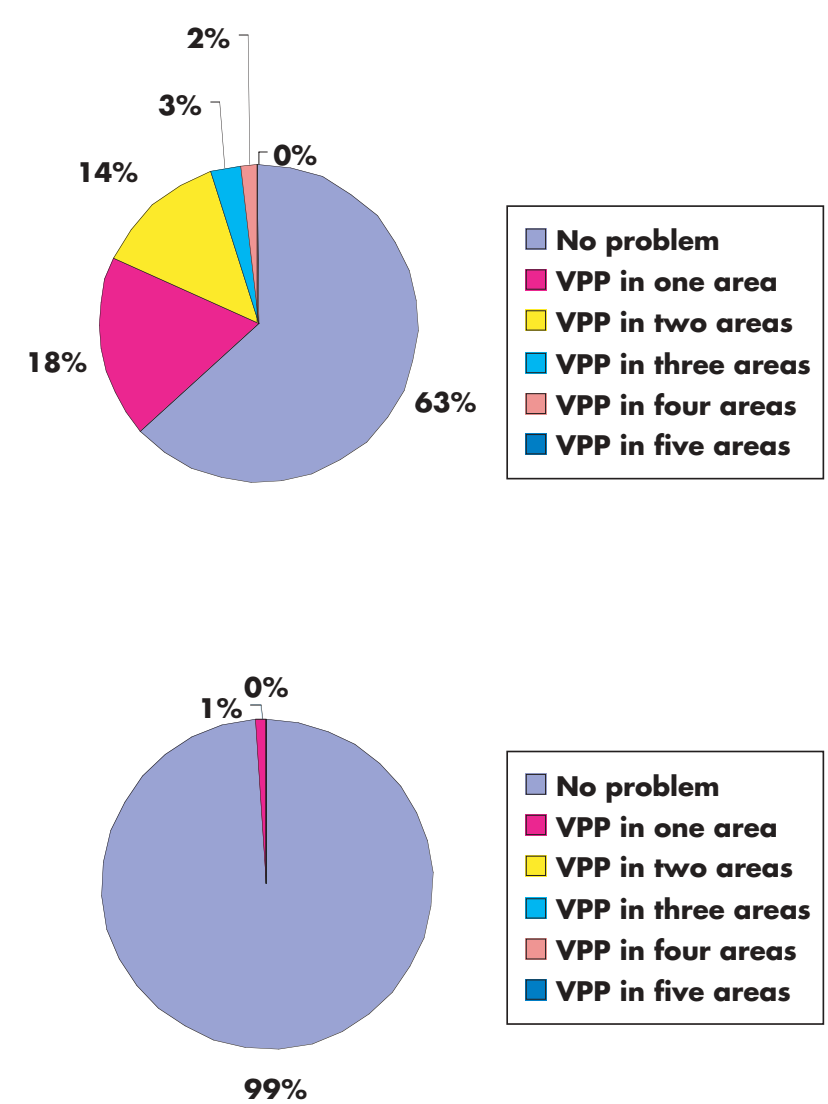

Figure 3 Proportion of adopted children ( $n=65)$ (top) and the reference group $(n=89)$ (bottom) who either exhibited no visuoperceptual problem (VPP) or had problems in one or more of the five areas tested (recognition, orientation, depth perception, motion perception, and/or simultaneous perception), as recorded by structured history taking.

another six children being referred for follow up care because of subnormal vision for various reasons.

\section{DISCUSSION}

In the present study, a high frequency of ocular and visual abnormalities was found in children adopted from eastern Europe. Overall, $78 \%$ of the children had significant ophthalmological findings including low VA, strabismus, amblyopia, reduced stereovision, refractive errors, congenital glaucoma, $\mathrm{ONH}$, and signs of cognitive visual problems. According to medical records from the birth countries, only $14 \%$ of the children had ocular findings of a more significant type. Hence, most of the ophthalmological disorders were undiagnosed before adoption. Previous reports on internationally adopted children have described single cases of strabismus and ONH. ${ }^{1}$ However, to our knowledge, no complete ophthalmological evaluation was performed in these studies.

Among the adopted children, signs of prenatal adverse events, such as prematurity and low birth weight, were found in this study. The frequency of SGA (birth weight $\leqslant-2$ SDS) in the study cohort was $46 \%(28 / 61)$ and the rate of children born preterm was $30 \%$. These findings are similar to those of other studies, showing a high prevalence of ocular and visual problems in children born preterm and/or with low birth weight. ${ }^{9-20}$ Among the adopted children born SGA, the rate of ophthalmic morbidity was $83 \%$ compared with $78 \%$ for the whole study cohort. It has been shown that preterm children have a higher risk of developing myopia and anisometropia than children born full term. ${ }^{10}$ This could not be confirmed in the present study; however, the number of children studied here is relatively small.

Furthermore, prematurity itself has also been associated with subnormal development of VA and strabismus. ${ }^{11-13} \mathrm{~A}$ study of 1151 children with extremely low birth weight (ELBW) $(\leqslant 1000 \mathrm{~g})$ has shown that ELBW infants are at significant risk of neurological morbidities, developmental delays, and functional abnormalities such as low VA in $9 \%{ }^{14}$ Altogether, 19 children in the present study had low VA $(\leqslant 0.5$ ( $\geqslant 0.3 \log$ MAR) in the best eye), 12 of whom were born preterm and/or SGA. In a study by O'Connor et $\mathrm{al}^{15}$ of low birth weight infants $(n=293)$, the prevalence of strabismus was found to be $20 \%$ and the esotropia:exotropia ratio $1: 1$. In contrast with $\mathrm{O}^{\prime}$ Connor et al's findings, 34\% of the adopted children born SGA in the present study had heterotropia and the ratio of esotropia:exotropia was 2.3:1. The ratio reported in the present study better corresponds to the ratio (2.6:1) reported in Kvarnström et $a l^{21}$ in their cohort of 413 children referred to an eye clinic by community visual screening in Sweden.

In addition, an increased incidence of sequelae such as impaired visuospatial attention and visuomotor function in preterm children has been reported by several authors. ${ }^{16-20}$ Hård et $a l^{19}$ found that in their study population, three times as many children born before the 29th gestational week than children born at term had low scores on a test of visual perception. Other reports have found no such difference. ${ }^{16} 20$ Visuoperceptual problems, according to a structured history taking, were noted in a considerable proportion (37\%) in our study. Twelve out of 27 adopted children born SGA (44\%) showed signs of cognitive visual problems.

According to the medical records from the countries of birth, there were indications of prenatal alcohol exposure in $33 \%$ of the adopted children. Albers and coworkers ${ }^{1}$ reported maternal alcohol abuse, as quoted from medical records from the birth countries, in 19\% of children adopted from eastern Europe. Fetal alcohol syndrome (FAS) has previously been associated with subnormal VA and strabismus, as have fundus abnormalities such as $\mathrm{ONH}$ and tortuosity of the retinal vessels, which have been found in almost $50 \%$ of cases with FAS. ${ }^{22-25}$ In the present study, four children had bilateral $\mathrm{ONH}$, and in three of these, a history of suspected prenatal alcohol exposure was documented. These three children had other ocular signs of FAS such as reduced vision, strabismus, and, in one of them, tortuosity of the retinal vessels was found. They were also born SGA. These signs taken together made them highly suspected of having alcohol related birth defects.

Previous studies regarding adopted children's physical and mental health have mainly been performed on children originating from Asia and South America. ${ }^{26-34}$ Children adopted from eastern Europe are a relatively new, increasing group of adoptees whose background differs in several respects from that of other international adoptees. Children from eastern Europe are often older at the time of adoption and have lived at orphanages for a longer period of time. Longitudinal studies are few and most studies are performed on children who have recently arrived in their new home country, which suggests that some diagnoses could have been missed or some condition has not yet been expressed at younger ages..$^{1-6}$ It was not possible to make a comparison in this study with within Sweden adoptees since such a group of adoptees is almost non-existent today. Whether the nonparticipants of the study $(n=23 / 99)$ differ in ophthalmological status cannot be ruled out and the reason why four nonrespondents and 6/19 parental refusals did not want to participate in the study is only speculative.

In conclusion, children adopted from eastern Europe have a high frequency of visual dysfunction and ocular pathology 
such as low VA, strabismus, refractive errors, ONH, and signs of visuoperceptual problems. On the basis of these results, we strongly recommend that an ophthalmological examination be performed among these children after arrival in their new home country.

\section{ACKNOWLEDGEMENTS}

This study was supported by the Göteborg Medical Society, the Allmänna Barnhuset, the W \& M Lundgrens Vetenskapsfond II, the M Thyselius fond för blind ungdom, Research and Development of the Region Västra Götaland, the Institute of Skaraborg, the Stiftelsen Samariten, and the Swedish Research Society (grant No 10863). The results have been presented in different parts at the annual meeting of the American Association of Pediatric Ophthalmology and Strabismus (AAPOS) in Orlando, FL, USA, in March 2001, at the 10th Nordic Pediatric Ophthalmology Congress held in Tromsö, Norway, in August 2001, at the European Pediatric Ophthalmology Society (EPOS) annual meeting held in Regensburg, Germany, in September 2001, at the Riksstämman meeting held in Göteborg, Sweden, in November 2002, and at the AAPOS annual meeting held in Hawaii, USA, in March 2003.

The authors would like to thank Cecilia Eriksson for her initial work focusing on children adopted from eastern Europe and Birgitta Melander, Carola Pfeiffer Mosesson, and Eva Rudholm for their technical assistance. Emma Jaensson and Gunnar Ekeroth of the Statiska Konsultgruppen, Göteborg, Sweden, are gratefully acknowledged for their help with the statistical analyses.

\section{Authors' affiliations}

M A Grönlund, E Aring, A Hellström, K Strömland, Institute of Clinical Neuroscience, Section of Ophthalmology, The Sahlgrenska Academy at Göteborg University, Göteborg, Sweden

M Landgren, Department of Pediatrics, Hospital of Skaraborg, Skövde, Sweden

\section{REFERENCES}

1 Albers LH, Johnson DE, Hostetter MK, et al. Health of children adopted from the former Soviet Union and eastern Europe. Comparison with preadoptive medical records. JAMA 1997;278:922-4.

2 Johnson DE, Miller LC, lverson S, et al. The health of children adopted from Romania. JAMA 1992;268:3446-51.

3 Hoksberger R, Van Dijkum C, Stoutjesdijk F. Experiences of Dutch families who parent an adopted Romanian child. J Dev Behav Pediatr 2002;23:403-9.

4 Rutter M, Andersen-Wood L, Beckett C, et al. Quasi-autistic patterns following severe early global privation. J Child Psychol Psychiatry 1999;4:537-49.

5 Rutter M, Andersen-Wood L, Beckett C, et al. Developmental catch-up and deficit, following adoption after severe global early privation. J Child Psychol Psychiatry 1998;4:465-76

6 Rutter ML, Kreppner JM, O'Connor T. Specificity and heterogeneity in children's responses to profound institutional privation. $\mathrm{Br} J$ Psychiatry 2001;179:97-103.

7 Hedin A, Olsson K. Letter legibility and the construction of a new visual acuity chart. Ophthalmologica 1984;189:147-56.

8 Dutton G, Ballantyne J, Boyd G, et al. Cortical visual dysfunction in children: a clinical study. Eye 1996;10:302-9.

9 Pennefather PM, Clarke MP, Strong NP, et al. Ocular outcome in children born before 32 weeks' gestation. Eye 1995;9:26-30.

10 Holmström G, el Azazi M, Kugelberg U. Ophthalmological long-term follow up of preterm infants: a population based, prospective study of the refraction and its development. Br J Ophthalmol 1998;82:1265-71.
11 Holmström G, el Azazi M, Kugelberg U. Ophthalmological follow up of preterm infants: a population based, prospective study of visual acuity and strabismus. Br J Ophthalmol 1999;83:143-50.

12 Schalii-Delfors NE, De Graaf MEL, Treffers WF, et al. Long term follow up of premature infants: detection of strabismus, amblyopia, and refractive errors. Br J Ophthalmol 2000;84:963-7.

13 O'Connor AR, Stephenson TJ, Johnson A, et al. Strabismus in children of birth weight less than $1701 \mathrm{~g}$. Arch Ophthalmol 2002;120:767-73.

14 Vohr BR, Wright LL, Dusick AM, et al. Neurodevelopmental and functional outcomes of extremely low birth weight infants in the National Institute of Child Health and Human Development Neonatal Research Network, 1993-1994. Pediatrics 2000;105:1216-26.

15 O'Connor AR, Stephenson TJ, Johnson A, et al. Long-term ophthalmic outcome of low birth weight children with and without retinopathy of prematurity. Pediatrics 2002;1:12-18.

16 Foreman N, Fielder A, Minshell C, et al. Visual search, perception, and visualmotor skills in "healthy" children born at 27-32 weeks' gestation. J Exp Child Psychol 1997:64:27-41.

17 Luoma L, Herrgård E, Martikainen A. Neurophysiological analysis of the visuomotor problems in children born preterm at $<32$ weeks of gestation: a 5year follow-up. Dev Med Child Neurol 1998;40:21-30.

18 Goyen T-A, Lui K, Woods R. Visual-motor, visual-perceptual, and fine motor outcomes in very-low-birthweight children at 5 years. Dev Med Child Neurol 1998;40:76-81.

19 Hård A-L, Niklasson A, Svensson E, et al. Visual function in school-aged children born before 29 weeks of gestation: a population-based study. Dev Med Child Neurol 2000;42:100-5.

20 Teplin SW, Burchinal M, Johnson-Martin N, et al. Neurodevelopmental, health, and growth status at age 6 years of children with birth weights less than 1001 grams. J Pediatrics 1991;118:768-77.

21 Kvarnström G, Jakobsson P, Lennerstrand G. Visual screening of Swedish children: an ophthalmological evaluation. Acta Ophthalmol Scand $2001 ; 79: 240-4$.

22 Strömland K. Ocular abnormalities in the fetal alcohol syndrome. Acta Ophthalmol 1985;171(Suppl):1-50

23 Chan $T$, Bowell $R, O^{\prime}$ Keefe $M$, et al. Ocular manifestations in fetal alcohol syndrome. Br J Ophthalmol 1991;75:524-6.

24 Miller MT, Israel J, Cuttone J. Fetal alcohol syndrome. J Pediatr Ophthalmol Strabismus $1981 ; 18: 6-15$

25 Hug TE, Fitzgerald KM, Cibis GW. Clinical and electroretinographic findings in fetal alcohol syndrome. J AAPOS 2000;4:200-4.

26 Verhulst FC, Althaus M, Versluis-den Bienman HJ. Problem behavior in international adoptees: I. An epidemiological study. J Am Acad Child Adolesc Psychiatry 1990;29:94-103.

27 Hostetter MK, Iverson S, Thomas W, et al. Medical evaluation of internationally adopted children. N Engl J Med 1991;7:479-85.

28 Proos LA, Hofvander $Y$, Wennqvist $K$, et al. A longitudinal study on anthropometric and clinical development of Indian children adopted to Sweden. I. Clinical and anthropometric condition at arrival. Ups J Med Sci 1992;97:79-92.

29 Proos LA, Hofvander $Y$, Wennqvist $K$, et al. A longitudinal study on anthropometric and clinical development of Indian children adopted to Sweden. II. Growth. Morbidity and development during two years after arrival in Sweden. Ups J Med Sci 1992;97:93-106.

30 Tuvemo T, Proos LA. Girls adopted from developing countries: a group at risk of early pubertal development and short final height. Implications for health surveillance and treatment. Ann Med 1993;25:217-19.

31 Cederblad M, Hook B, Irhammar M, et al. Mental health in international adoptees as teenagers and young adults. An epidemiological study. J Child Psychol Psychiat 1999:40:1239-48.

32 Hiern A, Lindblad F, Vinnerljung B. Suicide, psychiatric illness, and social maladjustment in intercountry adoptees in Sweden: a cohort study. Lancet 2002;360:443-8

33 Lindblad F, Hjern A, Vinnerljung B. Intercountry adopted children as young adults - a Swedish cohort study. Am J Orthopsychiat 2003;73:190-202.

34 Johansson-Kark M, Rasmussen F, Hjern A. Overweight among international adoptees in Sweden: a population based study. Acta Pediatr 2002;91:827-32. 